\title{
Should psychiatrists be more cautious about the long-term prophylactic use of antipsychotics?
}

Robin M. Murray, Diego Quattrone, Sridhar Natesan, Jim van Os, Merete Nordentoft, Oliver Howes, Marta Di Forti and David Taylor

\section{Summary}

Patients who recover from an acute episode of psychosis are frequently prescribed prophylactic antipsychotics for many years, especially if they are diagnosed as having schizophrenia. However, there is a dearth of evidence concerning the long-term effectiveness of this practice, and growing concern over the cumulative effects of antipsychotics on physical health and brain structure. Although controversy remains concerning some of the data, the wise psychiatrist should regularly review the benefit to each patient of continuing prophylactic antipsychotics against the risk of side-effects and loss of effectiveness through the development of supersensitivity of the dopamine $D_{2}$ receptor. Psychiatrists should work with their patients to slowly reduce the antipsychotic to the lowest dose that prevents the return of distressing symptoms. Up to $40 \%$ of those whose psychosis remits after a first episode should be able to achieve a good outcome in the long term either with no antipsychotic medication or with a very low dose.

\section{Declaration of interest}

R.M.M. and J.v.O. have received honoraria from Bristol-Myers Squibb, Janssen, Lilly, Roche, Servier and Lundbeck for lectures, and M.D.F. has received honoraria from Janssen and Lundbeck. O.H. has received investigator-initiated research funding from and/or participated in advisory/ speaker meetings organised by Astra-Zeneca, Autifony, Bristol-Myers Squibb, Eli Lilly, Heptares, Janssen, Lundbeck, Leyden Delta, Otsuka, Servier, Sunovion, Rand and Roche.

\section{Copyright and usage}

(c) The Royal College of Psychiatrists 2016.
There is no doubt that antipsychotic treatment is valuable in acute psychotic episodes. There is also considerable evidence that antipsychotics are useful for those with continuing positive psychotic symptoms. Indeed, the introduction of antipsychotics in the 1950s is credited with having contributed to the return to the community of many previously chronically ill patients from asylums, and the running down and eventual abolition of these institutions. ${ }^{1}$

However, a new era was ushered in by Leff \& Wing in 1971 when they reported an randomised controlled trial (RCT) of the prophylactic value of antipsychotics in preventing the relapse of people with schizophrenia. ${ }^{2}$ Subsequently, many other RCTs confirmed that relapse was less common in those who continued treatment with antipsychotics. Although most of these trials lasted for less than 1 year, ${ }^{3}$ it became common practice for those who had received a diagnosis of schizophrenia to remain on antipsychotics for many years.

However, increasing doubts have been raised about the long-term prophylactic use of antipsychotics. ${ }^{4}$ As with any drug treatment, the beneficial effects have to be balanced against the potential side-effects. This paper will therefore address five troublesome issues: (a) effects of antipsychotics on physical health, (b) effects of antipsychotics on brain structure, (c) efficacy of long-term antipsychotic use, (d) antipsychotic-induced dopamine receptor supersensitivity, and (e) treatment-resistant schizophrenia (TRS).

\section{Physical health}

People with schizophrenia die earlier than the rest of the population. ${ }^{5,6}$ Studies from several countries show that the trend of mortality rates in people with psychosis has not followed the same downward course as that of the general population, resulting in a widening disparity. ${ }^{7-10}$
Suicide accounts for part of the excess mortality, although the most obvious remediable cause is the excessive use of tobacco; illicit drug use, poor diet and lack of exercise are also implicated. However, the possibility that antipsychotics also contribute has attracted much attention recently. Antipsychotics can cause cardiac arrhythmias ${ }^{11,12}$ and induce dyslipidaemia and obesity, with activation of the cascade towards insulin resistance and diabetes. $^{13-15}$ Most second-generation antipsychotics (SGAs) confer a higher cardiometabolic risk than first-generation antipsychotics (FGAs), and some authors point out that the switch to SGAs from the mid-1990s has paralleled the widening of the mortality gap. ${ }^{8}$

However, there is still dispute over whether long-term antipsychotic prescription actually increases overall mortality. For example, data from Swedish nationwide registers show a lower mortality in patients with chronic schizophrenia receiving longterm antipsychotics than in those with similar duration of illness but no antipsychotic exposure. ${ }^{16}$ It could be that antipsychotics reduce suicides or facilitate better self-care - or simply, as Mace et $a l^{17}$ suggest, that taking antipsychotics 'may be a surrogate marker for overall healthy behaviour'.

\section{Implications}

In spite of the above controversy, there is enough evidence concerning the adverse effects of antipsychotics on physical health to compel psychiatrists to act. There are three obvious ways to address the risk. First, to prescribe, wherever possible, antipsychotics with a lower propensity to induce weight gain. Second, to facilitate a healthy diet and lifestyle from the start of treatment. Third, to reduce the use, or at least the dosage, of long-term antipsychotics. In implementing this last strategy, one must, of course, consider the possible impact on the mental health of each patient. 


\section{Structural brain changes}

Many people with schizophrenia show subtle developmental brain abnormalities at the onset of their illness. ${ }^{18}$ However, further brain changes occur in the years following the onset of the illness. These were interpreted initially as reflecting an intrinsic degenerative schizophrenic process. ${ }^{19}$ However, a number of reports have concluded that the majority, if not all, of these brain changes are a consequence of environmental factors; among these factors are antipsychotic medication, ${ }^{20-23}$ illicit drug use, ${ }^{24}$ cigarette smoking, ${ }^{25}$ obesity and diabetes. ${ }^{26}$ Animal studies have confirmed the effects of antipsychotics in decreasing cortical volume and have shown, at least in monkeys and rats, that the changes are not due to a loss of neurons. ${ }^{27-29}$

\section{Implications}

Long-term use of high-dose FGAs does carry a risk of decreasing cortical volume and increasing ventricular volume; low-dose antipsychotics and SGAs may carry less risk. ${ }^{30}$ These effects appear to be reversible on stopping antipsychotics. ${ }^{31,32}$ Some preclinical behavioural studies have suggested that chronic administration of antipsychotics can impair memory-related task performance, as well as spatial and working memory. ${ }^{33,34}$ Although the changes in grey matter observed in schizophrenia are correlated with deficits in cognitive domains, the latter have not been specifically linked to antipsychotics. ${ }^{35}$

In short, there is still no clear link between the antipsychoticassociated changes seen with magnetic resonance imaging (MRI) and cognitive decline or functional impairment. Therefore, until more research evidence is available, the jury remains out on what, if anything, we should do about the effects of antipsychotics on brain structure.

\section{Do antipsychotics improve long-term outcomes?}

Many RCTs have compared outcomes in those patients with schizophrenia continuing antipsychotics with those in whom the drugs were stopped. These 'discontinuation' studies uniformly show a greater likelihood of relapse in the latter group. ${ }^{36}$ Thus, a meta-analysis of 65 trials $^{3}$ concluded that 'antipsychotic maintenance treatment substantially reduces relapse risk in all patients with schizophrenia for up to 2 years of follow-up'. However, few studies have lasted longer than this, leading Leucht et al to point out that 'nothing is known about the very long-term effects of antipsychotic drugs compared to placebo' ${ }^{37}$ Thus, longterm 'maintenance' treatment with antipsychotics is based on hope rather than evidence.

New studies have shed light on this issue. Harrow ${ }^{38}$ repeatedly assessed the course of 70 young patients diagnosed with schizophrenia. Those 15 not prescribed antipsychotics over the 20 years showed significantly fewer psychotic symptoms than those 25 continuously on antipsychotics. Moilanen and colleagues, ${ }^{39}$ who followed up 74 patients with first-episode psychosis (FEP) in Finland, reported that after 10 years, the 24 not receiving medication had better clinical outcomes than those receiving antipsychotics. At the ten-year follow-up of 274 FEP patients in the UK ÆSOP sample, ${ }^{40}$ Morgan (personal communication, 2016) found that $18 \%$ of those who received a diagnosis of schizophrenia had not taken antipsychotics for two years and had no psychotic symptoms. Similarly, Wils \& Nordentoft (unpublished, further details available from M.N. on request) followed up 496 patients from the Danish OPUS study for 10 years after their first episode of schizophrenia spectrum disorder; $30 \%$ had remission of psychotic symptoms and were not taking antipsychotics.
There is a major confounder in all these studies, in that they were without randomisation. Consequently, those patients who were able to stop their medication may have had a milder illness than those who continued. Nevertheless, these studies demonstrate that a significant proportion of patients with psychosis manage to come off antipsychotic medication without detriment in the long term.

In a study less open to bias, Wunderink and colleagues selected a group of FEP patients who had been initially treated successfully with antipsychotics. After 6 months of remission, they were randomised for 18 months to either (a) an approach encouraging antipsychotic dose reduction or discontinuation; or (b) standard maintenance treatment: 18 months later, as expected, twice as many people had experienced a relapse in the reduction/ discontinuation group as in the maintenance group. ${ }^{41}$ However, by 7 years, the group who had been initially helped to reduce or discontinue their antipsychotics were reported to show twice the recovery rate of the maintenance patients. ${ }^{42}$

\section{Implications}

Naturalistic studies indicate that a significant minority of patients diagnosed as having psychosis and indeed schizophrenia can come off their antipsychotics without detriment in the long term. Wunderink and colleagues suggest that we can go further and try to help a larger proportion of patients to decrease or discontinue their antipsychotics. However, theirs was a small study, and it is important to emphasise that at 7 years, only $21 \%$ of patients in the dose reduction/discontinuation group had actually stopped their antipsychotics, while a similar proportion had taken a mean daily dose of less than $1 \mathrm{mg}$ of haloperidol for the past 2 years. In an accompanying editorial, McGorry et al concluded that 'It now seems probable for patients who achieve clinical remission from FEP that as many as $40 \%$ can achieve a good long term recovery with use of no or low-dose antipsychotic medication. ${ }^{43}$

Of course, the fact that some patients remain well without antipsychotics does not mean that the drugs do not help the remainder of the patients who either stay symptomless on antipsychotics or have their symptoms ameliorated by antipsychotics.

\section{Dopamine receptor supersensitivity}

The findings of Wunderink are curious and require some explanation. Why should antipsychotics be beneficial for up to 18 months but not at 7 years? Could it be that by then, antipsychotics have lost some of their effectiveness? To examine this possibility, we need to consider the mechanism of action of antipsychotics. All antipsychotics share the same essential property - they block $\mathrm{D}_{2}$ and $\mathrm{D}_{3}$ dopamine receptors. For many years, it was thought that the abnormality in schizophrenia lay in these receptors, and therefore it seemed logical to block them. However, it is now clear that most acutely psychotic patients show excessive presynaptic synthesis of dopamine in the striatum. ${ }^{44}$ Thus, antipsychotics do not address the primary locus of abnormality but rather have their beneficial effects downstream of it. Is it possible that prolonged prescription of antipsychotics sometimes induces changes in the $\mathrm{D}_{2} / \mathrm{D}_{3}$ receptor, which diminish the effectiveness of the drugs?

Animal studies suggest that this may be the case. ${ }^{45,46}$ Thus, Samaha et al found that, with continuous administration, haloperidol and olanzapine progressively lost their efficacy in suppressing amphetamine-induced locomotion and conditioned avoidance in rats; this was reversed temporarily by a further increase in antipsychotic dose. Antipsychotic failure was linked 
to a $20-40 \%$ increase in post-synaptic $\mathrm{D}_{2} / \mathrm{D}_{3}$ receptor density. ${ }^{47}$ Ginovart et $a l^{48}$ subsequently showed that high-dose antipsychotics lead to such an upregulation of $\mathrm{D}_{2} / \mathrm{D}_{3}$ receptors in cats; however, this did not occur with occupancy below $80 \%$ or with transient occupancy. Thus, $\mathrm{D}_{2} / \mathrm{D}_{3}$ upregulation may be a consequence of high-dose treatment. ${ }^{48}$

Post-mortem studies show increased $\mathrm{D}_{2} / \mathrm{D}_{3}$ receptor density in the brains of people with schizophrenia; however, most of the patients in these studies had been on long-term antipsychotics. ${ }^{49}$ A meta-analysis of in vivo positron emission tomography (PET) and single-photon emission computed tomography (SPECT) studies $^{50}$ demonstrated that patients who had previously received antipsychotics had an increase in $\mathrm{D}_{2} / \mathrm{D}_{3}$ receptor availability, but, importantly, antipsychotic-naive patients were no different from controls. One PET study showed $\mathrm{D}_{2} / \mathrm{D}_{3}$ receptor availability greater by $30 \%$ in patients who had received long-term dopamine antagonists relative to antipsychotic-naive patients. ${ }^{51}$

There have only been two longitudinal studies. Konig et al showed a $10 \%$ increase in $\mathrm{D}_{2} / \mathrm{D}_{3}$ receptor availability over 2 months in one patient treated with huge doses of chlorpromazine. ${ }^{52}$ A more recent study, ${ }^{53}$ which scanned eight antipsychotic-naive FEP patients, showed no elevation in $D_{2} / D_{3}$ receptor availability at baseline, but after 2-3 weeks of treatment (olanzapine $10 \mathrm{mg} /$ day or risperidone $2-3 \mathrm{mg} /$ day) there was an increase in $\mathrm{D}_{2} / \mathrm{D}_{3}$ receptors in some brain regions.

The idea that antipsychotics could induce supersensitivity of the $D_{2} / D_{3}$ receptor in some patients has been championed by Chouinard and colleagues, ${ }^{54,55}$ who pointed out as early as 1978 that antipsychotics induce a syndrome of supersensitivity of the motor system - tardive dyskinesia - and described what they termed 'drug-induced psychotic relapses' associated with tardive dyskinesia after long-term high doses of FGAs. ${ }^{56}$ They proposed that this supersensitivity causes tolerance to antipsychotics, such that eventually they no longer control psychotic symptoms. This is supported by a follow-up study of a cohort of 8620 patients, which reported worsening of psychosis with the onset of tardive dyskinesia. ${ }^{57}$

The evidence of antipsychotic-induced changes in the $\mathrm{D}_{2}$ receptor points to an intrinsic problem with discontinuation studies. This was noted by Carpenter and colleagues when they stated that 'once patients are placed on medication, they are less vulnerable to relapse if maintained on neuroleptics. But what if these patients had never been treated with drugs to begin with? We raise the possibility that antipsychotic medication may make some schizophrenic patients more vulnerable to future relapse than would be the case in the natural course of the illness. ${ }^{58}$

Moncrieff, who carried out a meta-analysis of patient withdrawal studies, concluded that 'antipsychotic discontinuation may also increase the risk of relapse over and above the risk because of the underlying disorder. ${ }^{59}$ Interestingly, there have been occasional reports of withdrawal psychosis occurring in people who have never had psychiatric problems but have been prescribed $\mathrm{D}_{2}$ blockers for other reasons. ${ }^{60-62}$

Unfortunately, there are no clinical studies examining whether relapse following antipsychotic withdrawal is linked to $D_{2} / D_{3}$ receptor changes. However, Joyce, who gave haloperidol to rats for 9 months, showed that the increase in $\mathrm{D}_{2}$ receptors persisted for at least 2 months after stopping antipsychotics. ${ }^{63}$ Converting rat months to their human equivalent, this would imply a period of increased vulnerability in patients following discontinuation of antipsychotics of more than a year. ${ }^{64}$ Such a vulnerability period would be consistent with views expressed by patient groups such as the Hearing Voices Network. ${ }^{65}$ They remind us that that many people diagnosed as having schizophrenia have successfully come off their antipsychotics, ${ }^{66}$ but point out that this can be initially difficult owing to agitation, insomnia and indeed recurrence of psychotic symptoms.

\section{Implications}

The results of animal studies are clear - dopamine $D_{2} / D_{3}$ receptor upregulation and resultant supersensitivity can occur with longterm use of antipsychotics. There are some neurochemical imaging studies of patients suggesting the development of $D_{2}$ supersensitivity; there is indirect evidence that this may be responsible for the decrease in efficacy of antipsychotics with their continuing prescription, and that it may contribute to relapse on stopping antipsychotics. However, there is surprisingly little longitudinal data, and methodological issues need to be addressed before a firm conclusion can be reached.

Interestingly, it seems that dopamine partial agonists do not induce $\mathrm{D}_{2}$ receptor supersensitivity in animals. ${ }^{67}$ Furthermore, there are clinical reports that switching from a $\mathrm{D}_{2}$ blocker to the partial agonist aripiprazole worsens psychosis, as would be expected in a supersensitivity state. ${ }^{68}$

There is an urgent need for neurochemical imaging studies addressing the question of dopamine supersensitivity in patients. We also need further RCTs to examine the risk of relapse after dose reduction and/or discontinuation of $\mathrm{D}_{2}$ blockers, as well as of partial $\mathrm{D}_{2}$ agonists, in order to establish guidelines on when and how antipsychotics can be safely reduced over time.

\section{Treatment-resistant schizophrenia}

In contrast to patients who respond to dopamine $\mathrm{D}_{2}$ blockers, neurochemical imaging shows that a proportion of patients with TRS do not show any abnormality of dopamine synthesis. It appears that such patients have generally never responded to $D_{2}$ blockers because they have nothing intrinsically wrong with their dopamine system. ${ }^{69,70}$

A second group of TRS patients have initially responded to antipsychotics but gradually lose this responsiveness. Several Japanese groups ${ }^{71,72}$ have suggested that supersensitivity due to upregulation of $\mathrm{D}_{2}$ receptors may be the cause of this treatment resistance. Here, it is worth pondering why clozapine is the most effective treatment for patients with TRS, when it is not especially effective for patients with FEP. ${ }^{73}$ Chouinard's idea that dopamine supersensitivity underlies both tardive dyskinesia and TRS reminds us that one of the most effective treatments for tardive dyskinesia is clozapine. Clozapine, of course, produces lower and more transient $\mathrm{D}_{2} / \mathrm{D}_{3}$ receptor occupancy than most other antipsychotics. $^{74}$ This allows the dopamine supersensitivity of the motor system to gradually resolve, and tardive dyskinesia to slowly fade. Is it possible that the effectiveness of clozapine for some patients with TRS relies on a similar mechanism?

\section{Implications}

Some patients diagnosed with TRS do not show dopamine dysregulation, and therefore their failure to respond to $\mathrm{D}_{2}$ blockade is hardly surprising. A second group may have developed TRS secondary to prolonged $\mathrm{D}_{2}$ blockade, and the effectiveness of clozapine for such patients may rely on its ability to control positive psychotic symptoms while $\mathrm{D}_{2}$ supersensitivity resolves.

By definition, people with TRS are not going to respond to $\mathrm{D}_{2}$ blockers. However, sadly, in practice such patients are frequently prescribed high doses of $\mathrm{D}_{2}$ blockers in the misguided hope that if a moderate dose is not effective then a larger dose may be so. We urgently need studies of those people with TRS who do not respond to clozapine to ascertain whether continuing them on 
non-clozapine antipsychotics has some partial benefit or just produces side-effects.

\section{Conclusions}

What is the wise psychiatrist to do faced with the concerns we have reviewed? He or she will treat acute psychosis with the minimum necessary dose of antipsychotics, employing weightsparing antipsychotics wherever possible; dopamine partial agonists have this property and may also be less likely to induce dopamine supersensitivity. Following recovery, the psychiatrist should work with each patient to decrease the dose to the lowest level compatible with freedom from troublesome psychotic symptoms; in a minority of patients, this level will be zero.

Such an approach requires ready access to non-pharmacological treatments. Many psychiatrists rely largely on antipsychotics, not because they dismiss the value of, for example, cognitive-behavioural therapy or vocational training, but rather because financial constraints limit the availability of such interventions. ${ }^{75}$ Psychiatrists need to campaign to ensure that their patients have access to all beneficial treatments. The greater availability of non-pharmacological treatments would enable clinicians to determine more objectively when the balance of advantage lies in stopping antipsychotics.

Finally, it is worth recalling that Leff \& Wing, who carried out the first RCT of long-term prophylaxis with antipsychotics concluded that ' $[\mathrm{m}]$ aintenance therapy seems of little value in patients with a good prognosis and in the severely ill, but it is of value in the indeterminate group between these two extremes. ${ }^{2}$ Of course, this historical view refers to non-clozapine antipsychotics and should be modified to suggest that the severely ill who do not respond to such drugs should be encouraged to try clozapine. Nevertheless, it is unfortunate that so little attention has been paid to this cautionary statement.

Robin M. Murray, FRS, FRCPsych, Diego Quattrone, MD, Sridhar Natesan, PhD, King's College London, Institute of Psychiatry, Psychology and Neuroscience, and NIHR Maudsley Biomedical Research Centre, London. UK; Jim van Os, PhD, MRCPsych, King's College London, Institute of Psychiatry, Psychology and Neuroscience, NIHR Maudsley Biomedical Research Centre, London, UK, and Department of Psychiatry and Psychology, Maastricht University Medical Center, The Netherlands; Merete Nordentoft, PhD, Mental Health Center, University of Copenhagen, Denmark; Oliver Howes, PhD, MRCPsych, King's College London, Copenhagen, Denmark; Oliver Howes, PhD, MRCPsych, King's College London,
Institute of Psychiatry, Psychology and Neuroscience, NIHR Maudsley Biomedical Research Centre, and MRC Clinical Sciences Centre, Imperial College London, London, UK; Marta Di Forti, PhD, MRCPsych, King's College London, Institute of Psychiatry, Psychology and Neuroscience, and NIHR Maudsley Biomedical Research Centre, London, UK; David Taylor, PhD, King's College London, Institute of Psychiatry, Psychology and Neuroscience, and NIHR Maudsley Biomedical Research Centre, London, UK

Correspondence: Robin M. Murray, Institute of Psychiatry, De Crespigny Park, London, SE5 8AF, UK. Email: robin.murray@kcl.ac.uk

First received 7 Feb 2016, final revision 11 Jul 2016, accepted 30 Jul 2016

\section{References}

1 Shorter E. A History of Psychiatry: From the Era of the Asylum to the Age of Prozac. John Wiley \& Sons, 1997.

2 Leff JP, Wing JK. Trial of maintenance therapy in schizophrenia. BMJ 1971; 3 599-604.

3 Leucht S, Tardy M, Komossa K, Heres S, Kissling W, Salanti G, et al. Antipsychotic drugs versus placebo for relapse prevention in schizophrenia: a systematic review and meta-analysis. Lancet 2012; 379: 2063-71.

4 Moncrieff J. Antipsychotic maintenance treatment: time to rethink? PLOS Med 2015; 12: e1001861.

5 Walker ER, McGee RE, Druss BG. Mortality in mental disorders and global disease burden implications: a systematic review and meta-analysis. JAMA Psychiatry 2015; 72: 334-41.
6 Brown S, Kim M, Mitchell C, Inskip H. Twenty-five year mortality of a community cohort with schizophrenia. Br J Psychiatry 2010; 196: 116-21.

7 Hoang U, Stewart R, Goldacre MJ. Mortality after hospital discharge for people with schizophrenia or bipolar disorder: retrospective study of linked English hospital episode statistics, 1999-2006. BMJ 2011; 343: d5422.

8 Saha S, Chant D, McGrath J. A systematic review of mortality in schizophrenia: is the differential mortality gap worsening over time? Arch Gen Psychiatry 2007; 64: 1123-31.

9 Lawrence D, Kisely S, Pais J. The epidemiology of excess mortality in people with mental illness. Can J Psychiatry 2010; 55: 752-60.

10 Laursen TM, Nordentoft M, Mortensen PB. Excess early mortality in schizophrenia. Annu Rev Clin Psychol 2014; 10: 425-48.

11 Frommeyer G, Eckardt L. Drug-induced proarrhythmia: risk factors and electrophysiological mechanisms. Nat Rev Cardiol 2016; 13: 36-47.

12 Ray WA, Chung CP, Murray KT, Hall K, Stein CM. Atypical antipsychotic drugs and the risk of sudden cardiac death. N Engl J Med 2009; 360: 225-35.

13 Henderson DC, Vincenzi B, Andrea NV, Ulloa M, Copeland PM. Pathophysiological mechanisms of increased cardiometabolic risk in people with schizophrenia and other severe mental illnesses. Lancet Psychiatry 2015; 2: 452-64

14 Stahl SM, Mignon L, Meyer JM. Which comes first: atypical antipsychotic treatment or cardiometabolic risk? Acta Psychiatr Scand 2009; 119: 171-9.

15 De Hert M, Detraux J, van Winkel R, Yu W, Correll CU. Metabolic and cardiovascular adverse effects associated with antipsychotic drugs. Nat Rev Endocrinol 2012; 8: 114-26.

16 Torniainen M, Mittendorfer-Rutz E, Tanskanen A, Bjorkenstam C, Suvisaari J, Alexanderson $\mathrm{K}$, et al. Antipsychotic treatment and mortality in schizophrenia. Schizophr Bull 2015; 41: 656-63.

17 Mace S, Dzahini O, Cornelius V, Anthony D, Stewart R, Taylor D. Antipsychotic use and unexpected death: a hospital-based case-control study. Acta Psychiatr Scand 2015; 132: 479-88.

18 Murray RM, Lewis SW. Is schizophrenia a neurodevelopmental disorder? BMJ (Clin Res Ed) 1987; 295: 681-2.

19 van Haren NE, Cahn W, Hulshoff Pol HE, Kahn RS. Schizophrenia as a progressive brain disease. Eur Psychiatry 2008; 23: 245-54.

20 Navari S, Dazzan P. Do antipsychotic drugs affect brain structure? A systematic and critical review of MRI findings. Psychol Med 2009; 39 : 1763-77.

21 Moncrieff J, Leo J. A systematic review of the effects of antipsychotic drugs on brain volume. Psychol Med 2010; 40: 1409-22.

22 Zipursky RB, Reilly TJ, Murray RM. The myth of schizophrenia as a progressive brain disease. Schizophr Bull 2013; 39: 1363-72.

23 Vita A, De Peri L, Deste G, Sacchetti E. Progressive loss of cortical gray matter in schizophrenia: a meta-analysis and meta-regression of longitudinal MRI studies. Trans/ Psychiatry 2012; 2: e190.

24 Rais M, Cahn W, van Haren N, Schnack H, Caspers E, Hulshoff Pol H, et al. Excessive brain volume loss over time in cannabis-using first-episode schizophrenia patients. Am J Psychiatry 2008; 165: 490-6.

25 Karama S, Ducharme S, Corley J, Chouinard-Decorte F, Starr JM, Wardlaw JM, et al. Cigarette smoking and thinning of the brain's cortex. Mol Psychiatry 2015; 20: 778-85

26 Katon W, Pedersen HS, Ribe AR, Fenger-Gron M, Davydow D, Waldorff FB, et al. Effect of depression and diabetes mellitus on the risk for dementia: a national population-based cohort study. JAMA Psychiatry 2015; 72: 612-9.

27 Dorph-Petersen KA, Pierri JN, Perel JM, Sun Z, Sampson AR, Lewis DA. The influence of chronic exposure to antipsychotic medications on brain size before and after tissue fixation: a comparison of haloperidol and olanzapine in macaque monkeys. Neuropsychopharmacology 2005; 30: 1649-61.

28 Vernon AC, Crum WR, Lerch JP, Chege W, Natesan S, Modo M, et al. Reduced cortical volume and elevated astrocyte density in rats chronically treated with antipsychotic drugs - linking magnetic resonance imaging findings to cellular pathology. Biol Psychiatry 2014; 75: 982-90.

29 Konopaske GT, Dorph-Petersen KA, Pierri JN, Wu Q, Sampson AR, Lewis DA. Effect of chronic exposure to antipsychotic medication on cell numbers in the parietal cortex of macaque monkeys. Neuropsychopharmacology 2007; 32: 1216-23.

30 Vita A, De Peri L, Deste G, Barlati S, Sacchetti E. The effect of antipsychotic treatment on cortical gray matter changes in schizophrenia: does the class matter? A meta-analysis and meta-regression of longitudinal magnetic resonance imaging studies. Biol Psychiatry 2015; 78: 403-12.

31 Boonstra G, van Haren NE, Schnack HG, Cahn W, Burger H, Boersma M, et al. Brain volume changes after withdrawal of atypical antipsychotics in patients with first-episode schizophrenia. J Clin Psychopharmacol 2011; 31: 146-53. 
32 Vernon AC, Natesan S, Crum WR, Cooper JD, Modo M, Williams SC, et al. Contrasting effects of haloperidol and lithium on rodent brain structure: a magnetic resonance imaging study with postmortem confirmation. Biol Psychiatry 2012; 71: 855-63.

33 Terry AV Jr, Gearhart DA, Warner SE, Zhang G, Bartlett MG, Middlemore ML, et al. Oral haloperidol or risperidone treatment in rats: temporal effects on nerve growth factor receptors, cholinergic neurons, and memory performance. Neuroscience 2007; 146: 1316-32.

34 Terry AV Jr, Hill WD, Parikh V, Evans DR, Waller JL, Mahadik SP. Differentia effects of chronic haloperidol and olanzapine exposure on brain cholinergic markers and spatial learning in rats. Psychopharmacology 2002; 164: 360-8.

35 Gur RE, Turetsky BI, Bilker WB, Gur RC. Reduced gray matter volume in schizophrenia. Arch Gen Psychiatry 1999; 56: 905-11.

36 Taylor M, Cavanagh J, Hodgson R, Tiihonen J. Examining the effectiveness of antipsychotic medication in first-episode psychosis. J Psychopharmacol 2012 26: $27-32$.

37 Leucht S, Tardy M, Komossa K, Heres S, Kissling W, Davis JM. Maintenance treatment with antipsychotic drugs for schizophrenia. Cochrane Database Syst Rev 2012; 5: CD008016.

38 Harrow M, Jobe $T H$, Faull RN. Does treatment of schizophrenia with antipsychotic medications eliminate or reduce psychosis? A 20-year multifollow-up study. Psychol Med 2014; 44: 3007-16.

39 Moilanen J, Haapea M, Miettunen J, Jaaskelainen E, Veijola J, Isohanni M et al. Characteristics of subjects with schizophrenia spectrum disorder with and without antipsychotic medication - a 10-year follow-up of the Northern Finland 1966 Birth Cohort study. Eur Psychiatry 2013; 28: 53-8.

40 Morgan C, Lappin J, Heslin M, Donoghue K, Lomas B, Reininghaus U, et al Reappraising the long-term course and outcome of psychotic disorders: the ÆESOP-10 study. Psychol Med 2014; 44: 2713-26.

41 Wunderink L, Nienhuis FJ, Sytema S, Slooff CJ, Knegtering R, Wiersma D. Guided discontinuation versus maintenance treatment in remitted firstepisode psychosis: relapse rates and functional outcome. J Clin Psychiatry 2007; 68: 654-61.

42 Wunderink L, Nieboer RM, Wiersma D, Sytema S, Nienhuis FJ. Recovery in remitted first-episode psychosis at 7 years of follow-up of an early dose reduction/discontinuation or maintenance treatment strategy: long-term follow-up of a 2-year randomized clinical trial. JAMA Psychiatry 2013; 70 913-20.

43 McGorry P, Alvarez-Jimenez M, Killackey E. Antipsychotic medication during the critical period following remission from first-episode psychosis: less is more. JAMA Psychiatry 2013; 70: 898-900.

44 Howes OD, Murray RM. Schizophrenia: an integrated sociodevelopmentalcognitive model. Lancet 2014; 383: 1677-87.

45 Smith RC, Davis JM. Behavioral evidence for supersensitivity after chronic administration of haloperidol, clozapine, and thioridazine. Life Sci 1976; 19 : 725-31

46 Grace AA. Dopamine system dysregulation and the pathophysiology of schizophrenia: insights from the methylazoxymethanol acetate model. Biol Psychiatry 2015; doi:10.1016/j.biopsych.2015.11.007.

47 Samaha AN, Seeman P, Stewart J, Rajabi H, Kapur S. "Breakthrough" dopamine supersensitivity during ongoing antipsychotic treatment leads to treatment failure over time. J Neurosci 2007; 27: 2979-86.

48 Ginovart N, Wilson AA, Hussey D, Houle S, Kapur S. $D_{2}$-receptor upregulation is dependent upon temporal course of $\mathrm{D}_{2}$-occupancy: a longitudinal ${ }^{11} \mathrm{C}$ raclopride PET study in cats. Neuropsychopharmacology 2009; 34: 662-71.

49 Zakzanis KK, Hansen KT. Dopamine $D_{2}$ densities and the schizophrenic brain. Schizophr Res 1998; 32: 201-6.

50 Howes OD, Kambeitz J, Kim E, Stahl D, Slifstein M, Abi-Dargham A, et al. The nature of dopamine dysfunction in schizophrenia and what this means for treatment. Arch Gen Psychiatry 2012; 69: 776-86.

51 Silvestri S, Seeman MV, Negrete JC, Houle S, Shammi CM, Remington GJ, et al. Increased dopamine $D_{2}$ receptor binding after long-term treatment with antipsychotics in humans: a clinical PET study. Psychopharmacology 2000; 152: $174-80$

52 Konig P, Benzer MK, Fritzche H. SPECT technique for visualization of cerebra dopamine D2 receptors. Am J Psychiatry 1991; 148: 1607-8.

53 Mizrahi R, Agid O, Borlido C, Suridjan I, Rusjan P, Houle S, et al. Effects of antipsychotics on D3 receptors: a clinical PET study in first episode antipsychotic naive patients with schizophrenia using $\left[{ }^{11} \mathrm{C}\right]-(+)-\mathrm{PHNO}$ Schizophr Res 2011; 131: 63-8.

54 Chouinard G, Jones BD, Annable L. Neuroleptic-induced supersensitivity psychosis. Am J Psychiatry 1978; 135: 1409-10.

55 Chouinard G, Chouinard VA. Atypical antipsychotics: CATIE study, druginduced movement disorder and resulting iatrogenic psychiatric-like symptoms, supersensitivity rebound psychosis and withdrawa discontinuation syndromes. Psychother Psychosom 2008; 77: 69-77.

56 Chouinard G, Annable L, Ross-Chouinard A. Supersensitivity psychosis and tardive dyskinesia: a survey in schizophrenic outpatients. Psychopharmaco Bull 1986; 22: 891-6.

57 Tenback DE, van Harten PN, Slooff CJ, van Os J. Worsening of psychosis in schizophrenia is longitudinally associated with tardive dyskinesia in the European Schizophrenia Outpatient Health Outcomes study. Compr Psychiatry 2007; 48: 436-40

58 Carpenter WT, McGlashan TH, Strauss JS. The treatment of acute schizophrenia without drugs: an investigation of some current assumptions. Am J Psychiatry 1977; 134: 14-20.

59 Moncrieff J. Does antipsychotic withdrawal provoke psychosis? Review of the literature on rapid onset psychosis (supersensitivity psychosis) and withdrawal-related relapse. Acta Psychiatr Scand 2006; 114: 3-13.

60 Roy-Desruisseaux J, Landry J, Bocti C, Tessier D, Hottin P, Trudel JF. Domperidone-induced tardive dyskinesia and withdrawal psychosis in an elderly woman with dementia. Ann Pharmacother 2011; 45: e51.

61 Lu ML, Pan JJ, Teng HW, Su KP, Shen WW. Metoclopramide-induced supersensitivity psychosis. Ann Pharmacother 2002; 36: 1387-90.

62 Seeman P. Yes, Breast is best but taper domperidone when stopping (e-letter). Br J Gen Pract 2014; January 15.

63 Joyce JN. $D_{2}$ but not $D_{3}$ receptors are elevated after 9 or 11 months chronic haloperidol treatment: influence of withdrawal period. Synapse 2001; 40 : 137-44.

64 Quinn R. Comparing rat's to human's age: how old is my rat in people years? Nutrition 2005; 21: 775-7.

65 Corstens D, Longden E, McCarthy-Jones S, Waddingham R, Thomas N. Emerging perspectives from the hearing voices movement: implications for research and practice. Schizophr Bull 2014; 40: S285-94.

66 Corstens D, Longden E, Rydinger B, Bentall R, van Os J. Treatment of hallucinations: a comment. Psychosis 2013; 5: 98-102.

67 Tadokoro S, Okamura N, Sekine Y, Kanahara N, Hashimoto K, Iyo M. Chronic treatment with aripiprazole prevents development of dopamine supersensitivity and potentially supersensitivity psychosis. Schizophr Bull 2012; 38: 1012-20.

68 Takaesu Y, Kishimoto T, Murakoshi A, Takahashi N, Inoue Y. Factors associated with discontinuation of aripiprazole treatment after switching from other antipsychotics in patients with chronic schizophrenia: a prospective observational study. Psychiatry Res 2016; 236: 71-4.

69 Demjaha A, Egerton A, Murray RM, Kapur S, Howes OD, Stone JM, et al. Antipsychotic treatment resistance in schizophrenia associated with elevated glutamate levels but normal dopamine function. Biol Psychiatry 2014; 75: e11-3.

70 Demjaha A, Murray RM, McGuire PK, Kapur S, Howes OD. Dopamine synthesis capacity in patients with treatment-resistant schizophrenia. Am J Psychiatry 2012; 169: 1203-10.

71 Suzuki T, Kanahara $\mathrm{N}$, Yamanaka $\mathrm{H}$, Takase $\mathrm{M}$, Kimura $\mathrm{H}$, Watanabe $\mathrm{H}$, et al. Dopamine supersensitivity psychosis as a pivotal factor in treatmentresistant schizophrenia. Psychiatry Res 2015; 227: 278-82.

72 Oda $\mathrm{Y}$, Kanahara N, Iyo M. Alterations of dopamine D2 receptors and related receptor-interacting proteins in schizophrenia: the pivotal position of dopamine supersensitivity psychosis in treatment-resistant schizophrenia. Int J Mol Sci 2015; 16: 30144-63.

73 Girgis RR, Phillips MR, Li X, Li K, Jiang H, Wu C, et al. Clozapine $v$. chlorpromazine in treatment-naive, first-episode schizophrenia: 9-year outcomes of a randomised clinical trial. Br J Psychiatry 2011; 199: 281-8.

74 Howes OD, Egerton A, Allan V, McGuire P, Stokes P, Kapur S. Mechanisms underlying psychosis and antipsychotic treatment response in schizophrenia: insights from PET and SPECT imaging. Curr Pharm Des 2009; 15: 2550-9.

75 Schizophrenia Commission. The Abandoned IIIness. Rethink, 2012. 